\title{
Impact of oligohydramnios on maternal and perinatal outcome: a comparative study
}

\section{Sreelakshmi U.*, Tushara Bindu, Subhashini T.}

\begin{abstract}
Department of Obstetrics and Gynecology, Mallareddy Medical College for Women and Hospital, Hyderabad,
\end{abstract} Telangana, India

Received: 24 May 2018

Accepted: 26 June 2018

\author{
*Correspondence: \\ Dr. Sreelakshmi U., \\ E-mail: dr.sreelakshmi@yahoo.com
}

Copyright: (C) the author(s), publisher and licensee Medip Academy. This is an open-access article distributed under the terms of the Creative Commons Attribution Non-Commercial License, which permits unrestricted non-commercial use, distribution, and reproduction in any medium, provided the original work is properly cited.

\begin{abstract}
Background: Oligohydramnios has got significant impact on perinatal outcome and maternal morbidity. Therefore, early detection and its management will help in reduction of perinatal morbidity and mortality, decreased operative interventions. Hence, the present study is undertaken to study the impact of oligohydromnios on perinatal-maternal outcome.

Methods: The present study was prospective comparative observational study conducted in the Department of Obstetrics and Gynaecology, Mallareddy Narayana Multispecialty Hospital, reputed teaching hospital from January 2015 to August 2017. The women were divided into study and control groups based on AFI, 100 cases were selected in each group.

Results: Out of the 200 women, included in the present study, in study group AFI $<5 \mathrm{~cm}$ was present in $51 \%$ of patients and AFI 5-8 cm in 49\% of patients. Doppler abnormalities found in study group $(\mathrm{n}=33) .32 \%$ of the patients in study group had non-reactive NST while in control group 8\%. Caesarean section was performed in $70 \%$ of cases in study group as compared to $9 \%$ in control group. Foetal distress was the most common indication for LSCS. There were no perinatal deaths in this study.

Conclusions: In this study amniotic fluid index of $\leq 5 \mathrm{~cm}$ was commonly associated with increased cesarean section rates, intrauterine growth restriction, Non-reactive NST and abnormal umbilical artery Doppler velocimetry studies. Hence, every case of oligohydramnios needs to be evaluated carefully, early detection and initiation of appropriate treatment and treat the cause if possible.
\end{abstract}

Keywords: Amniotic fluid index, Non stress test, Oligohydromnios, Perinatal outcome

\section{INTRODUCTION}

Successful outcome of obstetric wellbeing is assessed by obtaining healthy mother and child in modern obstetrics. ${ }^{1}$ Amniotic fluid provides a protective milieu for the growing foetus, cushioning it against mechanical and biological injury and allows proper growth and development. Clinical assessment of amniotic fluid volume at outpatient department itself is an initial step to identify high risk pregnancy and foetal wellbeing as variation in its amount has been related to a variety of pregnancy complications. ${ }^{2}$ The amniotic fluid volume estimation is the summation of influx and efflux of fluid within the amniotic space. Amniotic fluid volume can be measured by different methods; most commonly used being amniotic fluid index (AFI) evaluation using ultrasonography. Ultrasonography is a non-invasive test, can be applied on a large scale and can be used frequently for repeated amniotic fluid volume estimation. Quantification of amniotic fluid is an important component of the biophysical profile in ultrasound evaluation of foetal wellbeing, especially in the third 
trimester. $^{3}$ Phelan et al described amniotic fluid estimation by Amniotic fluid Index (AFI) through transabdominal ultrasonography using four quadrant techniques. ${ }^{4}$ Abnormalities of the AFV have been associated with adverse pregnancy outcomes. ${ }^{5,6}$ A drastic reduction in its quantity may indicate underlying placental insufficiency, which has definite implications on growing fetus. Phelan et al, Baron et al and Kwon et al defined oligohydramnios as AFI less than or equal to 5 $\mathrm{cm}$ and 5.1 to 8 as Borderline or marginal oligohydramnios. ${ }^{4,6,7}$ By quantification of amniotic fluid volume, better identification of foetus at high risk can be done. Oligohydramnios is caused by pregnancy induced hypertension $(\mathrm{PIH})$, congenital anomalies like renal agenesis, idiopathic; postdate pregnancy, infections, etc. Many studies have established that oligohydramnios is correlated with increased risk of congenital abnormalities, intrauterine growth retardation, meconium aspiration syndrome, low APGAR scores, severe birth asphyxia such as fetal distress and still births and increased incidence of caesarean section..$^{8-10}$

Hence, Oligohydramnios has got significant impact on perinatal outcome and maternal morbidity. Therefore, early detection and its management will help in reduction of perinatal morbidity and mortality at one end and decreased operative interventions at another end. Hence, the present study is undertaken to study the impact of oligohydromnios on perinatal-maternal outcome.

\section{METHODS}

The present study was prospective comparative observational study conducted in the Department of Obstetrics and Gynaecology, Mallareddy Narayana Multispecialty Hospital, reputed teaching hospital from January 2015 to August 2017.

Women attending the outpatient department and labour room at or after 37 weeks of gestation with singleton pregnancy, intact membranes, sure about gestation age was calculated by LMP in patients with regular cycles or by first trimester USG, without known uterine anomalies and having AFI measurement within 3 days of delivery included in this study. Women with congenital malformation, previous caesarean section, medical disorder like cardiac disease, intrauterine death of the foetus, multiple pregnancy, premature rupture of membranes and post-dated pregnancy were excluded from this study. The women were divided into study and control groups based on AFI. For present study 100 cases selected in each group after fulfilling above criteria.

- Study group: AFI: $<8$

- Control group: AFI: $8-15$

A written and informed consent was taken from all the study participants. A detailed history and thorough clinical examination was done on admission. Base line investigations, ultrasound examination was performed on all the subjects. Phelan method of four-quadrant technique was used for measurement of AFI. If the woman did not deliver within 3 days of ultrasound, a repeat ultrasound for measuring AFI was done. Once oligohydramnios was confirmed by measuring AFI, routine management in the form of rest in left lateral position, oral and intravenous hydration was given and simultaneously evaluated for underlying etiological factor and corrected if identified. Ante partum foetal surveillance was done by USG, NST, modified Biophysical profile and Umbilical Artery (UA) Doppler studies were also done if required at the same time.

Considering history, depending upon clinical assessment, Ante partum foetal surveillance reports, investigations and other obstetric factors were deciding factors for labour induction and elective/emergency caesarean section. Patients with spontaneous onset of labour were monitored with cardiotocography in the intrapartum period. Eventually, cases were analysed for maternal and perinatal outcome. Maternal outcome measured in the form of spontaneous onset /induced labour, mode of delivery, labour related events like non-reactive NST (abnormal fetal heart rate), and indication for emergency LSCS were studied. Perinatal outcome in the form of Apgar score at $1 \mathrm{~min}$ and $5 \mathrm{~min}$, liquor status (meconium staining), IUGR, birth weight and NICU admission were studied.

\section{RESULTS}

Mallareddy Narayana Multispecialty Hospital is one of the few tertiary care centres in Quthbullapur municipality, semi urban area. So many cases nearby localities were referred to this centre.

Table 1: Demographic characteristics in study and control groups.

\begin{tabular}{|lccll|}
\hline $\begin{array}{l}\text { Characteristics } \\
\text { Maternal age (years) }\end{array}$ & $\begin{array}{l}\text { Study } \\
\text { grouj }\end{array}$ & $\%$ & $\begin{array}{l}\text { Control } \\
\text { group }\end{array}$ & $\%$ \\
\hline$<20$ & 28 & 28 & 29 & 29 \\
\hline $20-30$ & 70 & 70 & 68 & 68 \\
\hline$>30$ & 2 & 2 & 3 & 3 \\
\hline Religion & & & & \\
\hline Hindu & 88 & 88 & 90 & 90 \\
\hline Muslim & 12 & 12 & 10 & 10 \\
\hline Booked & 44 & 44 & 83 & 83 \\
\hline Unbooked & 56 & 56 & 17 & 17 \\
\hline Gravidity & & & & \\
\hline Primigravida & 73 & 73 & 68 & 68 \\
\hline Multigravida & 27 & 27 & 32 & 32 \\
\hline Gestational age & $(\mathbf{w e e k s )}$ & & & \\
\hline $37-38$ & 16 & 16 & 8 & 8 \\
\hline $38-40$ & 84 & 84 & 92 & 92 \\
\hline AFI & & & & \\
\hline$<5$ & 51 & 51 & - & - \\
\hline $5-8$ & 49 & 49 & - & - \\
\hline
\end{tabular}


The study participants in both study and control group were compared in terms of age, religion, gravidity, booking status and period of gestation.

Table 2: Associated obstetrics risk factors.

\begin{tabular}{|lllll|}
\hline $\begin{array}{l}\text { Risk } \\
\text { factors }\end{array}$ & $\begin{array}{l}\text { Study } \\
\text { group }\end{array}$ & $\%$ & $\begin{array}{l}\text { Control } \\
\text { group }\end{array}$ & $\%$ \\
\hline $\begin{array}{l}\text { Isolated } \\
\text { oligohydromnios }\end{array}$ & 15 & 15 & - & - \\
\hline $\begin{array}{l}\text { Severe anemia } \\
\text { Pre-eclampsia }\end{array}$ & 18 & 18 & 10 & 10 \\
\hline $\begin{array}{l}\text { Gestational } \\
\text { diabetes }\end{array}$ & 2 & 2 & - & - \\
\hline $\begin{array}{l}\text { Hypothyroidism } \\
\text { IUGR (Intra } \\
\text { uterine growth }\end{array}$ & 11 & 11 & 7 & 7 \\
\hline $\begin{array}{l}\text { restriction) } \\
\text { Placental } \\
\text { abruption }\end{array}$ & 6 & 6 & - & 8 \\
\hline $\begin{array}{l}\text { Fever } \\
\text { complicating } \\
\text { pregnancy }\end{array}$ & 2 & 2 & - & - \\
\hline \begin{tabular}{l} 
More than \\
\hline
\end{tabular} & & 17 & 8 & - \\
\hline
\end{tabular}

More than one risk factor presents in one patient.

Table 3: Mode of delivery in study and control groups.

\begin{tabular}{|llllll|}
\begin{tabular}{|l} 
Mode of \\
delivery
\end{tabular} & $\begin{array}{l}\text { Study } \\
\text { group } \\
\mathbf{N}=100\end{array}$ & $\begin{array}{l}\text { Control } \\
\text { group } \\
\mathbf{N}=100\end{array}$ & $\%$ & p-value \\
\hline $\begin{array}{l}\text { Vaginal } \\
\text { delivery }\end{array}$ & 29 & 29 & 88 & 88 & $<0.0001$ \\
\hline $\begin{array}{l}\text { Instrumental } \\
\text { vaginal } \\
\text { delivery }\end{array}$ & 1 & 1 & 3 & 3 & 0.312 \\
\hline $\begin{array}{l}\text { Emergency } \\
\text { LSCS }\end{array}$ & 59 & 59 & 9 & 9 & $<0.0001$ \\
\hline $\begin{array}{l}\text { Elective } \\
\text { LSCS }\end{array}$ & 11 & 11 & 0 & 0 & 0.013 \\
\hline
\end{tabular}

LSCS: Lower uterine segment caesarean section
Table 1 was showing demographic characteristics in both groups. Out of the 200 women, included in the present study, in study group AFI $<5 \mathrm{~cm}$ was present in $51 \%$ of patients and AFI $5-8 \mathrm{~cm}$ in $49 \%$ of patients. Table 2 showing associated maternal risk factors. Placental insufficiency is the main underlying mechanism for the development of oligohydromnios in study group. Figure: 1 showing Doppler abnormalities in study group $(n=33)$. $32 \%$ of the patients in study group had non-reactive NST while in control group $8 \%$ had non-reactive NST. Table 3 showing mode of delivery in study and control groups.

Caesarean section was performed in $70 \%$ of cases in study group as compared to $9 \%$ in control group. A chi square statistic test was applied to know the significance of correlation between mode of delivery and AFI, $p$ value was less than 0.0001 ; this indicated the presence of a very strong and significant correlation between the AFI and mode of delivery.

Table 4: Distribution of indications for caesarean section in study and control groups.

\begin{tabular}{|lllll|}
\hline $\begin{array}{l}\text { Indications for } \\
\text { caesarean } \\
\text { section }\end{array}$ & $\begin{array}{l}\text { Study } \\
\text { group } \\
n=70\end{array}$ & $\%$ & $\begin{array}{l}\text { Control } \\
\text { group } \\
\text { n=9 }\end{array}$ & $\%$ \\
\hline $\begin{array}{l}\text { Foetal distress } \\
\begin{array}{l}\text { Malpresentation } \\
\text { (breech) }\end{array}\end{array}$ & 32 & 45.71 & 8 & 88.89 \\
\hline $\begin{array}{l}\text { Failed } \\
\text { induction }\end{array}$ & 12 & 17.14 & - & - \\
\hline $\begin{array}{l}\text { Non-progress } \\
\text { of labour }\end{array}$ & 3 & 4.28 & 1 & 11.11 \\
$\begin{array}{l}\text { Cephalo pelvic } \\
\text { disproportion }\end{array}$ & 3 & 4.28 & - & - \\
\hline $\begin{array}{l}\text { Absent diastolic } \\
\text { flow }\end{array}$ & 11 & 15.7 & - & - \\
\hline $\begin{array}{l}\text { Reversal of } \\
\text { diastolic flow }\end{array}$ & 5 & 7.1 & - & - \\
\hline
\end{tabular}

Table 4 shows distribution of indications for caesarean section in study and control groups. Foetal distress was the most common indication for LSCS.

Table 5: Perinatal outcome.

\begin{tabular}{|c|c|c|c|c|c|}
\hline Perinatal outcome & Study group, $\mathbf{N}=100$ & $\%$ & Control group, $\mathbf{N}=100$ & $\%$ & p-value \\
\hline IUGR & 32 & 32 & 8 & 8 & 0.0001 \\
\hline \multicolumn{6}{|l|}{ Apgar } \\
\hline$<7$ at $1 \mathrm{~min}$ & 34 & 34 & 17 & 17 & 0.006 \\
\hline$<7$ at $5 \mathrm{~min}$ & 21 & 21 & 9 & 9 & 0.017 \\
\hline Non-Reactive NST & 32 & 32 & 8 & 8 & $<0.0001$ \\
\hline $\begin{array}{l}\text { Meconeum stained liquor } \\
\text { aspiration }\end{array}$ & 31 & 31 & 13 & 13 & 0.002 \\
\hline NICU Admission & 23 & 23 & 16 & 16 & 0.212 \\
\hline Induction of labour & 32 & 32 & 8 & 8 & $<0.0001$ \\
\hline
\end{tabular}




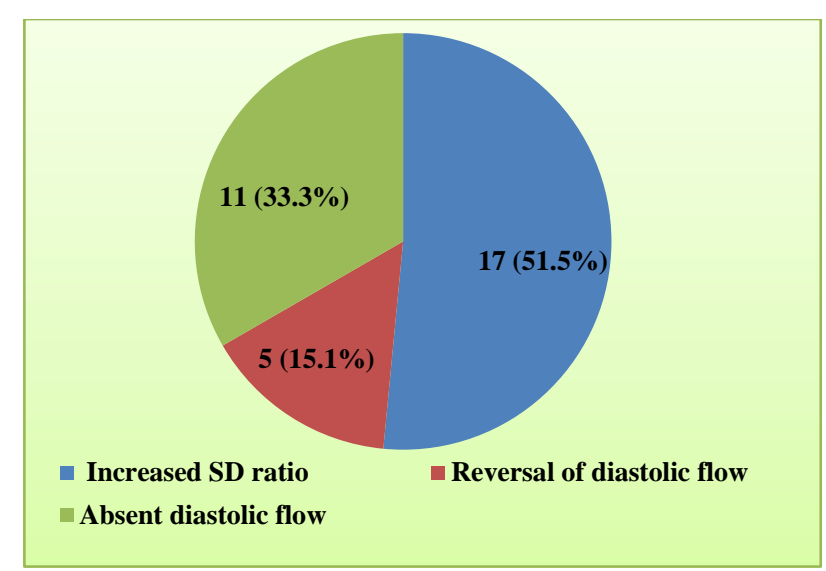

Figure 1: Doppler abnormalities in study group $(n=33)$.

Table 5 shows perinatal outcome. There were no perinatal deaths in this study. Among neonatal outcomes, induction of labour, meconeum stained liquor aspiration, non-reactive NST and Apgar score $<7$ at 1 min in study group were statistically significant $(\mathrm{p}<0.01)$.

\section{DISCUSSION}

Many studies have proven that oligohydramnios is correlated well with increased risk of Maternal morbidity, perinatal morbidity and mortality. Estimation of amniotic fluid volume is an integral part of antenatal foetal surveillance. ${ }^{11}$ Majority of study participants were in age group between 20-30 years. Demographic factors like age, parity, religion and gestational age were comparable in both groups. In present study $56 \%$ of cases in study group and $27 \%$ of cases in control group were unbooked. While in Mathuriya $\mathrm{G}$ et al study $88 \%$ in study group, $68 \%$ in control group were unbooked. The incidence of oligohydramnios was $73 \%$ in primigravida in present study. ${ }^{12}$ Kaur $\mathrm{P}$ et al, found that the incidence of oligohydramnios was $60 \%$ in primigravida which is comparable to the present study. ${ }^{13}$ Medical disorders like pre-eclampsia, hypothyroidism were risk factors to cause oligohydromnios in this study. Chronic placental insufficiency is the main underlying mechanism, leading to oligohydramnios. In present study pre-eclampsia was seen in $18 \%$ cases in study group and $8 \%$ of cases in control group. In Chate $\mathrm{P}$ et al study hypertensive disorders found in $8 \%$ of oligohydromnios cases only. ${ }^{14}$ Abruptio placenta was observed in $6 \%$ of present study and similar incidence was reported by Chandra $\mathrm{P}$ et al (7.69\%). ${ }^{15}$ Hypothyroidism (14.6\% versus $11 \%$ ) was seen in study group by Vidyasagar $\mathrm{V}$ and Chutani $\mathrm{N}$ and present study. ${ }^{16}$

Induction of labour was seen $32 \%$ of women with low AFI in study group as compared to control group $8 \%$ (chi square test: 9.56 and p value:0.002). Similar to Singhal SR et al study significantly higher induction of labour was seen in low AFI group $72 \%$ as compared to control group $12 \% .^{17}$

The most common indication for LSCS was foetal distress followed by failed induction and Ultrasound Doppler abnormalities in study group. While in control group foetal distress followed by non-progress of labour. In present study study group underwent LSCS in $70 \%$ of cases, while in control group 9\% undergone LSCS (chi square test: 77.85 and $p$ value: 0.0001 ). Similar to Mathuriya et al study $65 \%$ of the study cases and only $10 \%$ of controls underwent LSCS. ${ }^{12} 90 \%$ of the controls were delivered vaginally in both studies.

In Ranjita $\mathrm{G}$ et al study caesarean section rate was $54 \%$ in the oligohydramnios group as compared to control group $26 \% .{ }^{18}$ Chaudhary $\mathrm{R}$ et al study reported $51 \%$ underwent LSCS in cases, while $22 \%$ underwent LSCS in controls. ${ }^{19}$

Controversies encountered in relation to oligohydramnios and meconium-stained amniotic fluid. In present study induction of labour, non-reactive NST, meconium stained liquor aspiration, IUGR and $1 \mathrm{~min}$ Apgar score $<7$ were statistically significant difference found between study and control groups.

Table 6: Perinatal outcome in different studies.

\begin{tabular}{|c|c|c|c|c|c|c|c|c|}
\hline \multirow{2}{*}{ Studies } & \multicolumn{2}{|c|}{ Non-reactive NST } & \multicolumn{2}{|c|}{ NICU admission } & \multicolumn{2}{|l|}{ IUGR } & \multicolumn{2}{|c|}{$\begin{array}{l}\text { Meconeum stained } \\
\text { liquor }\end{array}$} \\
\hline & Study & Control & Study & Control & Study & Control & Study & Control \\
\hline Ranjita $\mathrm{G}$ et al & $42 \%$ & $15 \%$ & $28 \%$ & $18 \%$ & $62 \%$ & $25 \%$ & $18 \%$ & $12 \%$ \\
\hline Bhagat et al & $32 \%$ & $9.7 \%$ & $36 \%$ & $24 \%$ & $56 \%$ & $21.7 \%$ & $16 \%$ & $14.9 \%$ \\
\hline Bachhav AA et al & $65 \%$ & $24 \%$ & $33 \%$ & $10 \%$ & $30 \%$ & $11 \%$ & $18 \%$ & $1 \%$ \\
\hline Sangeetha K & $10 \%$ & $0 \%$ & $68 \%$ & $50 \%$ & - & - & $18 \%$ & $8 \%$ \\
\hline Present study & $32 \%$ & $8 \%$ & $23 \%$ & $16 \%$ & $17 \%$ & $8 \%$ & $31 \%$ & $17 \%$ \\
\hline
\end{tabular}

Outcomes like meconium stained liquor, 1-min Apgar score <7, IUGR and admission to NICU were not statistically different in the oligohydramnos group from the normal group in Ranjita et al study. NICU admissions 
in study group were $15 \%$ in cases and $11 \%$ in controls in Chaudhary R et al study.

In present study birth weight $<2.5 \mathrm{kgs}$ observed in $32 \%$ of cases in study group compared to $8 \%$ in control group ( $\mathrm{p}$ value $=0.0001)$. Bhagat et al in their study found that $56 \%$ neonate in low AFI group had birth weight less than $2.5 \mathrm{~kg}$ as compared to $21.7 \%$ in control group. ${ }^{20}$ In contrast to the present study, Sultana et al in their study observed that the difference in low birth weight was not significant between the two groups of AFI ( $p$ value $=0.4) .{ }^{21}$

\section{Table 7: AFI as a screening test to detect foetal} distress.

\begin{tabular}{|lcc|}
\hline Groups & LSCS & Vaginal \\
\hline Study & $70($ a) & $30($ b) \\
\hline Control & 9 (c) & $91($ d) \\
\hline
\end{tabular}

Sensitivity: $\times 100=\times 100=88.60 \%$ Specificity: $\times 100=\times 100=$ $75.20 \%$; Positive predictive value: $\times 100=\times 100=70 \%$; Negative predictive value: $\times 100=\times 100=91 \%$

Table 7 shows AFI as a screening test to detect foetal distress. AFI $<8 \mathrm{~cm}$ as a screening test in predicting fetal distress during labor requiring LSCS, has a sensitivity of $88.6 \%$, specificity $75.2 \%$, positive predictive value $70 \%$ and negative predictive value of $91 \%$.

In Kaur P et al study AFI in study cases as a screening test in predicting foetal distress during labour requiring LSCS, has a sensitivity of $68 \%$, specificity $60 \%$, positive predictive value $48 \%$ and negative predictive value of $78 \% .^{22}$ A test with high sensitivity and negative predictive value makes it a good screening test. Variations in incidences of perinatal and maternal outcome could be because of differences in the selection criteria, the selection of cases for the study and chosen design for the sample size.

\section{CONCLUSION}

Amniotic fluid volume is a predictor to identify pregnancies at risk of poor perinatal outcomes and its decrease is associated with increased risk of perinatal morbidity and mortality. In this study amniotic fluid index of $\leq 5 \mathrm{~cm}$ was commonly associated with increased caesarean section rates, intrauterine growth restriction, Non-reactive NST and abnormal umbilical artery Doppler velocimetry studies. Hence, every case of oligohydramnios needs to be evaluated carefully, early detection and initiation of appropriate treatment and treat the cause if possible. Proper parental counselling and individualized decision to be taken according to the case regarding timing and mode of delivery, continuous intrapartum foetal monitoring and good neonatal care for optimum perinatal outcome. However, multicentric randomized controlled trials are needed to define at what threshold levels of AFI to predict adverse perinatal outcome and guide management accordingly.

\section{ACKNOWLEDGMENTS}

Authors would like to thank Department of Obstetrics and Gynaecology and Department of Radiology, Mallareddy Medical College for Women and Hospital, Suraram, Hyderabad, Telangana state, India.

Funding: No funding sources

Conflict of interest: None declared

Ethical approval: The study was approved by the Institutional Ethics Committee

\section{REFERENCES}

1. Manning FA. Antepartum fetal testing: a critical appraisal. Curr Opin Obstet Gynecol. 2009;21(4):348-52.

2. Chamberlain PF, Manning FA, Morrison I. The relationship of marginal and decreased amniotic fluid volumes to perinatal outcome. Am J Obstet Gynecol. 1984;150(3):245-9.

3. Bhagat M, Chawla I. correlation of amniotic fluid index with perinatal outcome. Ind J Obstet Gynecol. 2014;64(1):32-5.

4. Phelan JP, Smith CV, Broussard P, Small M. Amniotic fluid volume assessment with the fourquadrant technique at 36-42 weeks gestation. J Reprod Med. 1987;32(7):540-2.

5. Rutherford SE, Phelan JP, Smith CV, Jacobs N. The four-quadrant assessment of amniotic fluid volume: an adjunct to antepartum fetal heart rate testing. Obstet Gynecol. 1987;70:353-6.

6. Baron C, Morgan MA, Garite TJ. The amniotic fluid volume assessed intrapartum on perinatal outcome. Am J Obstet Gynecol. 1995;173:167-74.

7. Kwon JY, Kwon HS, Kim YH, Park YW. Abnormal Doppler velocimetry is related to adverse pregnancy outcome for borderline amniotic fluid index in the third trimester. J Obstet Gynecol Res. 2006;32:5459.

8. Nath J, Jain M, Najam R. A clinical study on oligohydramnios in the third trimester of pregnancy with special emphasis on the perinatal outcome. J Evol Med Dental Sci. 2013;2(39):7386-91.

9. Bangal VB, Giri PA, Sali BM. Incidence of oligohydramnios during pregnancy and its effects on maternal and perinatal outcome. JPBMS. 2011;12(5):1-4.

10. Bachhav AA, Manjushri W. Low amniotic fluid index at term as a predictor of adverse perinatal outcome. J Obstet Gynecol India. 2014;64(2):120-3.

11. Ott WJ. Current perspective in antenatally surveillance ultrasound. Rev Obst Gynaecol. 2003;3:1-180.

12. Mathuriya G, Verma M, Rajpoot S. Comparative study of maternal and fetal outcome between low and normal amniotic fluid index at term. Int J Reprod Contracept Obstet Gynecol. 2017;6:640-4. 
13. Kaur P, Desai DA, Taraiya A. A study on the perinatal outcome in cases of oligohydramnios. Int $\mathrm{J}$ Reprod Contracept Obstet Gynecol. 2016;5:98-109.

14. Chate P, Khatri M, Hariharan C. Pregnancy outcome after diagnosis of oligohydramnios at term. Int $\mathrm{J}$ Reprod Contracept Obstet Gynecol. 2013;2:23-6.

15. Chandra P, Kaur SP, Hans DK, Kapila AK. The impact of amniotic fluid volume assessed intrapartum on perinatal outcome. Obstet Gynae Today. 2000;5(8):478-81.

16. Vidyasagar V, Chutani N. Fetomaternal outcome in cases of oligohydramnios after 28 weeks of pregnancy. Int J Reprod Contracept Obstet Gynecol 2015; 4: 152-6.

17. Singhal SR, Gupta R, Sen J. Low amniotic fluid index as a predictor of adverse perinatal outcome: an indian perspective. Clinics Mother Child Health. 2015;12:201.

18. Ranjita G, Sandhyarani B. Correlation of Oligohydramnios with Perinatal Outcome. J Med Res Prac. 2017;6(3):93-5.
19. Chaudhary R, Dhama V, Singh S, Singh M. Correlation of reduced amniotic fluid index with neonatal outcome. Int $\mathbf{J}$ Reprod Contracept Obstet Gynecol. 2017;6:2401-6.

20. Bhagat M, Chawla I. correlation of amniotic fluid index with perinatal outcome. Ind J Obstet Gynecol. 2014;64(1):32-5.

21. Sultana S, Khan AMN, Akhtar KKA, Aslam M. Low amniotic fluid index in high-risk pregnancy and poor apgar score at birth. J Coll Physicians Surg Pak. 2008;18:630-4.

22. Kaur P, Desai DA, Taraiya A. A study on the perinatal outcome in cases of oligohydramnios. Int $\mathbf{J}$ Reprod Contracept Obstet Gynecol. 2016;5:98-109.

Cite this article as: Sreelakshmi U, Bindu T, Subhashini T. Impact of oligohydramnios on maternal and perinatal outcome: a comparative study. Int J Reprod Contracept Obstet Gynecol 2018;7:3205-10. 